\title{
Subjective Opinions of Dental Attractiveness and Orthodontic Treatment Need among Nigerian Adolescents
}

\author{
Elfleda Aikins ${ }^{1}$, Oluranti daCosta ${ }^{2}$, Chukwudi Onyeaso ${ }^{1}$, Michael Isiekwe ${ }^{2}$ \\ ${ }^{I}$ (Department of Child Dental Health, College of Health Sciences, University of Port Harcourt, Nigeria ) \\ ${ }^{2}$ (Department of Child Dental Health, College of Medicine, University of Lagos, Nigeria)
}

\begin{abstract}
:
Introduction: The aim of this study was to evaluate the opinions of a cross-section of 12-18 year - old Nigerians about dental aesthetics and to compare the report with their self-perceived need for orthodontic treatment.

Methods: A structured questionnaire was administered to 612 12-18 year - old Nigerian adolescents who were randomly selected from 6 secondary schools in South-South Nigeria to assess their opinions of dental aesthetics, whilst the Aesthetic Component (AC) of the Index of Orthodontic Treatment Need (IOTN) was used to assess their self-perceived orthodontic treatment need.

Results: Majority (78.1\%) of the population expressed satisfaction with the arrangement of their teeth, whilst $82 \%$ did not perceive any need for orthodontic treatment (AC Grades 1-4). Their self-perceived orthodontic treatment need was found to increase as their satisfaction with the arrangement of their teeth decreased.

Conclusions and recommendations: Although majority of the adolescents realized the importance of dental aesthetics, there was a general low awareness of the presence of their malocclusions. We are recommending that populations in this area be more enlightened on the presence and treatment of malocclusion.
\end{abstract}

Keywords: Opinion, Dental attractiveness, Treatment need, Nigeria

\section{Introduction}

\section{Introduction}

Favourable dental aesthetics (attractiveness) have been found to be important because well-aligned teeth and a pleasing smile reflect positive status at all social levels, and irregular or protruding teeth reflect a negative status. ${ }^{1,2}$ However, perception of dental aesthetics varies among individuals and communities depending on their socio-cultural norms. What is an acceptable dental appearance for one person may not be acceptable for another, as in the case of the midline diastema which is considered as a malocclusion in Caucasian cultures, ${ }^{3.4}$ but is believed to be a sign of beauty in many African cultures. ${ }^{5-11}$ In addition, dissatisfaction with dental appearance is broadly related to the severity of the occlusal irregularities, ${ }^{3,4,12}$ but there are differences in the recognition and evaluation of the dental features. ${ }^{5}$

In Nigeria, where orthodontic services are mainly confined to the South-West, there is an increased awareness of dental aesthetics in that part of the country, which could be linked to the presence of the dental schools and practicing orthodontists in the region. However, with such services recently becoming available in South-South Nigeria, there is thus a great need for increased awareness of dental aesthetics, which will possibly subsequently increase the demand for treatment.

The aim of this study was to evaluate the opinions of a cross-section of 12-18 year - old Nigerians residing in South-South Nigeria about dental aesthetics and to compare the report with their self - perceived need for orthodontic treatment.

\section{Methods}

\section{Methods}

This cross-sectional study was conducted using an anonymous structured questionnaire to assess the opinions of the respondents about their dental aesthetics on one hand while self-perceived need for orthodontic treatment was assessed using the Aesthetic Component (AC) of the Index of Orthodontic Treatment Need (IOTN) on the other hand. The questionnaire was distributed among a sample of randomly selected school children in 6 public schools in Rivers State, Nigeria, which were selected by ballot from a list obtained from the Rivers State Ministry of Education. Informed consent was obtained from the participants.

The data was collected during school hours. A pre-tested self-administered questionnaire was used to capture the subjects' perceptions of the attractiveness of their occlusions in Likert scale. Comprehensive verbal instructions were given before distribution of the questionnaires. Any questions raised by the subjects were also answered before collection. The questionnaire had two sections, the first section asked for demographic characteristics, particularly date of birth, sex and nationality. The second section dealt with the children's awareness of their own occlusions, including questions on their satisfaction with the arrangement and 
appearance of their teeth, the importance of well-aligned teeth and whether and what they would like to change about their teeth. The questions were scaled and scored with 3 or 5 points, as follows:

1. Are you satisfied with the arrangement of your teeth?(1婏等y satisfied,2婏 satisfied,3婏 I do not care, 4婏 dissatisfied, and 5婏very dissatisfied)

2. Do you think your teeth look better or worse than most of your friends? (1婏Much better,

2婏better, 3婏equal, 4婏worse, and 5 婏much worse)

3. Do you consider well-aligned teeth important for overall facial appearance? (1婏 very important, 2婏mportant, 3 婏 does not matter, 4婏not important and 5婏not important at all).

4. Is there anything you would want to change about your teeth? (1婏Yes 2婏No３婏 I do not know.)

5. What would you want to change? (1婏Colour of my teeth 2.Arrangement of my teeth 3婏Size of my teeth.)

The AC ${ }^{13}$ has a scale of 10 coloured photographs showing different levels of dental attractiveness, with grade 1 representing the most attractive and grade 10 the least attractive. According to Richmond et al, ${ }^{14}$ grades $1-4$ represent no or little aesthetic need, grades 5-7 borderline / moderate aesthetic need, and grades 8-10 a definite aesthetic need for orthodontic treatment. The self perception of orthodontic treatment need was evaluated by asking each student to identify which photograph of the AC scale most closely matched the appearance of their anterior teeth.

\subsection{Statistical analysis}

The data was entered into a microcomputer and Statistical Package for Social Sciences Version 17.0 for Windows 2009, SPSS, Inc., Chicago, Illinois was used to generate descriptive statistics. Chi square was employed to compare the subjects self-perception of dental aesthetics and self-assessment of orthodontic treatment need. The level of significance was set at 0.05 .

\section{Results}

\section{Results}

\subsection{Socio-demographic results}

The population consisted of 299 (48.9\%) male and 313 (51.1\%) female students. All subjects were Nigerians aged 12 to 18 years with a mean age of $15.0 \pm 2.0$ years in permanent dentition and none of them had undergone any form of orthodontic treatment. A total of 630 questionnaires were distributed. Six hundred and twelve participants (97\%) were eventually employed, whilst 18 were excluded from the analysis due to incomplete data and presence of primary teeth.

\subsection{Subjective opinions of dental aesthetics}

Over three-quarters $(78.1 \%)$ of the population expressed satisfaction with the arrangement of their teeth, $71.2 \%$ would like to have their teeth straightened, whilst $81.4 \%$ of the respondents considered straight teeth important and $80.3 \%$ thought their teeth looked better than their friends (TABLE 1).

TABLE 2 shows the results of self-perceived orthodontic treatment need of the participants. About $82 \%$ scored themselves as not having any need for orthodontic treatment (AC scores 1-4) whilst $10.9 \%$ scored a moderate need (AC scores 5-7) and 6.5\% a definite need (AC scores 8-10). The overall mean AC score was 3.3 \pm 2.1 , mean $\mathrm{AC}$ score for male students was $3.3 \pm 2.1$ whilst that for female students was $3.4 \pm 2.0$.

There were some statistically significant associations between the participants' subjective opinions of dental aesthetics and their self- assessment of orthodontic treatment need [TABLE 3]. The subjects selfassessment of treatment need was found to increase as their satisfaction with the arrangement of their teeth decreased. Those that were very dissatisfied with their teeth arrangement were almost three times more likely to assess themselves as having a need for orthodontic treatment (Odd ratio $=2.64, p=0.01)$.

A greater need for treatment was expressed among the students that wanted to have their teeth straightened, though this was not significant. However, $90 \%$ of the population that indicated they would 'definitely not' want their teeth straightened did not assess themselves as having a need for treatment. This finding was significant (Odd ratio $=0.48, \mathrm{p}=0.04)$.

The students' opinions about whether straight teeth were important for facial beauty did not have any association with their self- assessment of treatment need $(p>0.05)$. There was a significant relationship between the assessment of the arrangement of their teeth and their self- perceived need for treatment. The students that perceived their teeth to be equal to their peers were twice as likely to have a self- perceived need for treatment $($ Odd ratio $=2.00, p=0.03)$, whilst those who said that their teeth were much worse than their peers perceived the need for treatment almost four times more than other groups (Odd ratio $=3.49, \mathrm{p}=0.02)$.

The proportion of the studied population who thought they needed to be treated by an orthodontist were also more likely to perceive a need for treatment $(20.7 \%)$ than those who did not think that they needed professional help (10.8\%), (Odd ratio=1.64, $\mathrm{p}=0.02)$. 
About ninety percent $(87 \%)$ of those who did not want to change anything about their teeth did not perceive a need for treatment. This finding was significant (Odd ratio $=0.60, \mathrm{p}=0.03$ ). Also, the students that indicated they would like to change the arrangement of their teeth were more than twice as likely to assess themselves as needing treatment than those that wanted to change the colour or size of their teeth.

Table 1: Subjective opinions of the respondents with respect to their dental aesthetics

\begin{tabular}{|c|c|c|}
\hline Subjective Opinion & Frequency & Percent \\
\hline \multicolumn{3}{|c|}{ Satisfaction with teeth arrangement } \\
\hline Very satisfied & 299 & 48.9 \\
\hline Satisfied & 179 & 29.2 \\
\hline Do not care & 28 & 4.6 \\
\hline Dissatisfied & 74 & 12.1 \\
\hline Very dissatisfied & 32 & 5.2 \\
\hline Total & 612 & 100 \\
\hline \multicolumn{3}{|c|}{ Would want teeth straightened } \\
\hline Definitely & 265 & 43.3 \\
\hline Probably & 171 & 27.9 \\
\hline Do not care & 21 & 3.4 \\
\hline Probably not & 65 & 10.6 \\
\hline Definitely not & 90 & 14.7 \\
\hline Total & 612 & 100 \\
\hline \multicolumn{3}{|c|}{ Consider straight teeth important } \\
\hline Very important & 372 & 60.8 \\
\hline Important & 126 & 20.6 \\
\hline Does not matter & 37 & 6.0 \\
\hline Not important & 52 & 8.5 \\
\hline Not important at all & 25 & 4.1 \\
\hline Total & 612 & 100 \\
\hline \multicolumn{3}{|c|}{ Comparing teeth with friend's } \\
\hline Much better & 214 & 35.0 \\
\hline Better & 277 & 45.3 \\
\hline Equal & 53 & 8.7 \\
\hline Worse & 56 & 9.2 \\
\hline Much worse & 12 & 2.0 \\
\hline Total & 612 & 100 \\
\hline \multicolumn{3}{|c|}{ Think orthodontist is needed } \\
\hline Yes & 334 & 54.6 \\
\hline No & 195 & 31.9 \\
\hline Don't know & 83 & 13.6 \\
\hline Total & 612 & 100 \\
\hline \multicolumn{3}{|c|}{ Would want to change something about teeth } \\
\hline Yes & 348 & 56.9 \\
\hline No & 236 & 38.6 \\
\hline Don't know & 28 & 4.6 \\
\hline Total & 612 & 100 \\
\hline \multicolumn{3}{|c|}{ What respondent wants to change } \\
\hline Colour of teeth & 226 & 64.9 \\
\hline Arrangement of teeth & 75 & 21.6 \\
\hline Size of teeth & 47 & 13.5 \\
\hline Total & 348 & 100 \\
\hline
\end{tabular}

Table 2: Distribution of AC assessment by participants

\begin{tabular}{|c|c|c|c|}
\hline \multirow[t]{2}{*}{ Variable } & \multicolumn{3}{|c|}{ Frequency (\%) } \\
\hline & Male & Female & Total \\
\hline \multicolumn{4}{|c|}{ Self assessment of need by participants } \\
\hline $1-4$ & $244(81.6)$ & $261(83.4)$ & $505(82.5)$ \\
\hline $8-10$ & $23(7.7)$ & $17(5.4)$ & $40(6.5)$ \\
\hline Total & $299(100)$ & $313(100)$ & $612(100)$ \\
\hline Mean & $3.3 \pm 2.1$ & $3.4 \pm 2.0$ & $3.3 \pm 2.1$ \\
\hline
\end{tabular}


Table 3: Associations between subjective opinions of dental aesthetics and self-assessment of orthodontic treatment need according to the Aesthetic Component of the Index of Orthodontic Treatment Need

\begin{tabular}{|c|c|c|c|c|c|c|c|}
\hline \multirow[t]{2}{*}{ Subjective Opinions } & \multicolumn{2}{|c|}{ Self assessment of need (\%) } & \multirow[t]{2}{*}{$\chi^{2}$} & \multirow{2}{*}{$\begin{array}{l}\text { Odd } \\
\text { ratio }\end{array}$} & \multicolumn{2}{|c|}{$95 \% \mathrm{CI}$} & \multirow[t]{2}{*}{$\mathbf{p}$} \\
\hline & $\begin{array}{l}\text { Need } \\
(n=107)\end{array}$ & $\begin{array}{l}\text { No } \\
(n=505)\end{array}$ & & & Lower & Upper & \\
\hline \multicolumn{8}{|l|}{ Satisfaction with teeth arrangement } \\
\hline Very satisfied & $45(15.1)$ & $254(84.9)$ & 2.40 & 0.72 & 0.46 & 1.12 & 0.12 \\
\hline Satisfied & $27(15.1)$ & $152(84.9)$ & 1.01 & 0.78 & 0.47 & 1.29 & 0.32 \\
\hline Do not care & $6(21.4)$ & $22(78.6)$ & 0.32 & 1.30 & 0.46 & 3.50 & 0.61 \\
\hline Dissatisfied & $18(24.3)$ & $56(75.7)$ & 2.73 & 1.62 & 0.87 & 2.99 & 0.10 \\
\hline Very dissatisfied & $11(34.4)$ & $21(65.6)$ & 6.68 & 2.64 & 1.15 & 5.97 & $0.01 *$ \\
\hline \multicolumn{8}{|l|}{ Would want teeth straightened } \\
\hline Definitely & $51(19.2)$ & $214(80.8)$ & 1.01 & 1.24 & 0.80 & 1.92 & 0.32 \\
\hline Probably & $35(20.5)$ & $136(79.5)$ & 1.46 & 1.32 & 0.82 & 2.11 & 0.23 \\
\hline Do not care & $2(9.5)$ & $19(90.5)$ & 0.96 & 0.49 & 0.08 & 2.21 & 0.56 \\
\hline Probably not & $10(15.4)$ & $55(84.6)$ & 0.22 & 0.84 & 0.39 & 1.78 & 0.64 \\
\hline Definitely not & $9(10.0)$ & $81(90.0)$ & 4.10 & 0.48 & 0.22 & 1.03 & $0.04 *$ \\
\hline \multicolumn{8}{|l|}{ Consider straight teeth important } \\
\hline Very important & $64(17.2)$ & $308(82.8)$ & 0.05 & 0.95 & 0.61 & 1.49 & 0.82 \\
\hline Important & $27(21.4)$ & $99(78.6)$ & 1.71 & 1.38 & 0.82 & 2.31 & 0.19 \\
\hline Does not matter & $7(18.9)$ & $30(81.1)$ & 0.06 & 1.11 & 0.43 & 2.74 & 0.81 \\
\hline Not important & $5(9.6)$ & $47(90.4)$ & 2.44 & 0.48 & 0.16 & 1.29 & 0.12 \\
\hline Not important at all & $4(16.0)$ & $21(84.0)$ & 0.04 & 0.90 & 0.25 & 2.83 & 0.84 \\
\hline \multicolumn{8}{|l|}{ Comparing teeth with friend's } \\
\hline Much better & $31(14.5)$ & $183(85.5)$ & 2.05 & 0.72 & 0.44 & 1.16 & 0.15 \\
\hline Better & $45(16.2)$ & $232(83.8)$ & 0.54 & 0.85 & 0.55 & 1.33 & 0.46 \\
\hline Equal & $15(28.3)$ & $38(71.7)$ & 4.71 & 2.00 & 1.01 & 3.95 & $0.03 *$ \\
\hline Worse & $11(19.6)$ & $45(80.4)$ & 0.20 & 1.17 & 0.55 & 2.45 & 0.66 \\
\hline Much worse & $5(41.7)$ & $7(58.3)$ & 4.96 & 3.49 & 0.94 & 12.53 & $0.02 *$ \\
\hline \multicolumn{8}{|l|}{ Think orthodontist is needed } \\
\hline Yes & $69(20.7)$ & $265(79.3)$ & 5.14 & 1.64 & 1.04 & 2.59 & $0.02 *$ \\
\hline No & $21(10.8)$ & $174(89.2)$ & 8.94 & 0.46 & 0.27 & 0.79 & $0.00^{*}$ \\
\hline Don't know & $17(12.5)$ & $66(79.5)$ & 0.59 & 1.25 & 0.67 & 2.34 & 0.44 \\
\hline \multicolumn{8}{|c|}{ Would want to change something about teeth } \\
\hline Yes & $67(19.3)$ & $281(80.7)$ & 1.75 & 1.34 & 0.85 & 2.10 & 0.19 \\
\hline No & $31(13.1)$ & $205(86.9)$ & 5.03 & 0.60 & 0.37 & 0.96 & $0.03 *$ \\
\hline Don't know & $9(32.1)$ & $19(67.9)$ & 4.37 & 2.35 & 0.95 & 5.67 & 0.07 \\
\hline What respondent wants to change & $(n=67)$ & $(n=281)$ & & & & & \\
\hline Colour of teeth & $32(14.2)$ & $194(85.8)$ & 10.76 & 0.41 & 0.23 & 0.73 & $0.00 *$ \\
\hline Arrangement of teeth & $23(30.7)$ & $52(69.3)$ & 8.01 & 2.30 & 1.23 & 4.31 & $0.01 *$ \\
\hline Size of teeth & $12(25.5)$ & $35(74.5)$ & 1.38 & 1.53 & 0.70 & 3.31 & 0.24 \\
\hline
\end{tabular}

*significant

\section{Discussion}

4. Discussion

The majority of patients with malocclusions seek orthodontic treatment during adolescence mainly for aesthetic reasons. ${ }^{15}$ Teenagers, in particular have been found to attach great importance to an attractive dental appearance ${ }^{3,16,17,18,19}$ For this reason, we decided to assess the opinions of 12-18 year olds.

4.1 Subjective opinions of dental aesthetics

Generally, the importance of dental aesthetics was realized by the studied population with $81.4 \%$ of them considering straight teeth as very important or important for overall facial appearance. This is comparable to the findings of Mugonzibwa et al. ${ }^{5}$ In this study, $78.1 \%$ of the participants indicated that they were satisfied with the arrangement of their teeth, whilst $17.3 \%$ were dissatisfied and $4.6 \%$ did not care about the arrangement of their teeth at all. Onyeaso and Sanu, ${ }^{18}$ in a previous Nigerian study conducted on 577 randomly selected secondary school adolescents aged 12 to 17 years, reported that $83.5 \%$ of the sample population were satisfied with their dental aesthetics while, $16.5 \%$ of the population were dissatisfied, which is comparable to what was found in this study. The apparent difference in the levels of satisfaction may be due to the increased response options available in this study, where the participants were given the opportunity to state 'I do not care' and not just whether they were satisfied or dissatisfied. In Latvia, lower levels of satisfactions: $63 \%$ and $67 \%$ were reported among 12-13 year - olds by Riga and Daugvapils respectively, ${ }^{19}$ whilst in Poland in a study conducted on 12 year - olds, $61.9 \%$ expressed satisfaction, $6 \%$ did not care and $26 \%$ were dissatisfied. ${ }^{20}$ These lower values are probably due to the increased level of knowledge and awareness of the participants about 
orthodontics and dental aesthetics, unlike the studied population, making them much more aware of the presence of any malocclusion. It is also probable that some of them had prior orthodontic treatment, which the sample in this study did not have access to, and so were much more aware of minor malocclusion which would cause them to be less satisfied with their own aesthetics. It has been reported that subjects that have undergone orthodontic treatment are more critical of their dental aesthetics. ${ }^{21}$

In this study, self-assessment of orthodontic treatment need using the $\mathrm{AC}$ was found to have a significant relationship with various aspects of the questionnaire. There was a significant relationship between the respondents' $\mathrm{AC}$ grades and their level of satisfaction with their dental aesthetics, with those expressing dissatisfaction more likely to recognize they had a need for treatment. Those respondents that were 'definitely not' interested in having their teeth straightened and did not want to change anything about their teeth were less likely to indicate a need for treatment. Meanwhile, those who thought they needed an orthodontist to straighten their teeth and thought their teeth were equal or looked much worse than their peers recognized their orthodontic treatment need more than those who did not think so. Also, the respondents that wanted to change the arrangement of their teeth were more than two times likely to recognize their need for treatment.

Worthy of note also is the fact that about two-thirds of the adolescents that wanted to change 'something about their teeth' wanted to change the colour of their teeth and these individuals were less likely to indicate a need for orthodontic treatment. This can be attributed to information obtained from the media by various manufacturers of toothpaste on the importance of white teeth. Many of the children actually indicated that they would want their teeth to be 'pure white'! Meanwhile, only about one-fifth of the population wanted to change the arrangement of their teeth. There is, therefore, a need for more enlightenment on malocclusion and the practice of orthodontics in our environment.

These associations reveal that the students were adequately able to use the $\mathrm{AC}$ to assess their relative need for treatment. It also makes a case for the subjective opinions of prospective patients to be taken into consideration when drawing up treatment plans for patients in addition to the normative opinion.

5. Conclusions

\section{Conclusion}

Majority of the adolescents (81.4\%) realized the importance of dental aesthetics though there was a low awareness of the presence of their malocclusions. Most of the students were more concerned about the colour of their teeth. In addition, most of the respondents who expressed a desire to change the arrangement of their teeth also perceived a greater need for treatment. There is an obvious need for increased enlightenment about malocclusion and orthodontics in Rivers State, Nigeria. We recommend that such enlightenment be carried out in schools.

\section{References}

[1]. Shaw WC. The influence of children's dentofacial appearance on their social attractiveness as judged by peers and lay adults. Am J Orthod 1981; 67: 399- 415

[2]. Shaw WC, Rees G, Dawe M, Charles CR. The influence of dentofacial appearance on the social attractiveness of young adults. Am J Orthod 1985; 87: 21- 26.

[3]. Helm S, Petersen PE, Kreiborg S, Solow B. Effect of separate malocclusion traits on concern for dental appearance. Community Dent Oral Epidemiol 1986; 14: 217-220.

[4]. Kerosuo H, Hausen H, Laine T, Shaw WC. The influence of incisal malocclusion on the social attractiveness of young adults in Finland. Eur J Orthod 1995; 17:505-512.

[5]. Mugonzibwa EA, Kuijpers-Jagtman AM, Van’t Hof MA, Kikwulu EN. Perceptions of dental attractiveness and orthodontic treatment need among Tanzanian children. Am J Orthod Dentofacial Orthop 2004; 125:426- 434.

[6]. Otuyemi OD, Ogunyinka A, Dosumu O, Cons NC, Jenny J, Kohout FJ, Jakobsen J. Perceptions of dental aesthetics in the United States and Nigeria. Community Dent Oral Epidemiol 1988; 26:418-420.

[7]. Kerosuo H, Laine T, Kerosuo E, Ngassapa D, Honkala E. Occlusion among a group of Tanzanian urban schoolchildren. Community Dent Oral Epidemiol 1988; 16: 306-309.

[8]. Diagne F, Ba I, Ba-Diop K, Yam AA, Ba-Tamba A. Prevalence of malocclusion in Senegal. Community Dent Oral Epidemiol 1993; 22: 325-326.

[9]. Abu-Affan AH, Wisth PJ. Malocclusion in 12-year old Sudanese children. Odontostomatal Trop 1990; 13:87-93

[10]. Isiekwe MC. Maxillary midline diastema in Nigerians. Nig Dent J 1983;17:4-6.

[11]. Sanu OO. The Prevalence and Predisposing Factors of Midline Diastema in School Children in Southwest Nigeria. Nigerian Journal of Health Sciences 2002; 2:11-14.

[12]. Albarakati SF. Self-perception of malocclusion of Saudi patients using the aesthetic component of the IOTN index. Pak Oral Dental J 2007; 27: 45-51.

[13]. Brook PH, Shaw WC. The development of an Index of Orthodontic Treatment Priority. Eur J Orthod 1989; 11: 309- 320.

[14]. Richmond S, Buchanan IB, Burden JB, O'Brien KD, Andrews M, Roberts CT, Turbill EA. Calibration of dentists in the use of occlusal indices. Community Dent Oral Epidemiol 1995; 11:309-320.

[15]. Onyeaso CO, Utomi IL, Ibekwe T. Emotional effects of malocclusion in Nigerian orthodontic patients. J Contemp Dent Pract 2005; 6:1-10.

[16]. Onyeaso CO, Sanu OO. Psychosocial implications of malocclusion among 12-18 year old Secondary School Children in Ibadan, Nigeria. Odontostomatol Trop 2005; 109:39-48.

[17]. Onyeaso CO, Arowojolu MO. Perceived, desired and normatively determined orthodontic treatment needs among orthodontically untreated Nigerian adolescents. West Afr J Med 2003; 22:5-9. 
[18]. Onyeaso CO, Sanu OO. Perception of personal dental appearance in Nigerian adolescents. Am J Orthod Dentofacial Orthop 2005; 127: 700- 706.

[19]. Liepa A, Urtane I, Richmond S, Dunstan F. Orthodontic Treatment Need in Latvia. Eur J Orthod 2003; 25: $279-284$.

[20]. Grzywacz I. The value of the aesthetic component of the index of orthodontic treatment need in the assessment of subjective orthodontic treatment need. Eur J Orthod 2003;25: 57-63.

[21]. Ren Y, Boxum C, Sandham A. Patients Perceptions, Treatment Need and Complexity of Orthodontic Re-Treatment. Eur J Orthod $2009 ; 31: 189-195$ 